\section{Effects of Discovery, Iteration, and Collaboration in Laboratory Courses on Undergraduates' Research Career Intentions Fully Mediated by Student Ownership}

\author{
Lisa A. Corwin, ${ }^{\dagger}$ Christopher R. Runyon, ${ }^{\ddagger}$ Eman Ghanem, $\$$ Moriah Sandy," \\ Greg Clark," Gregory C. Palmer," Stuart Reichler," Stacia E. Rodenbusch," and \\ Erin L. Dolan ${ }^{\text {T* }}$ \\ 'Department of Ecology and Evolutionary Biology, University of Colorado, Boulder, CO 80309;

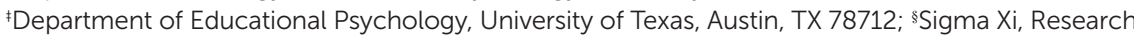 \\ Triangle Park, NC 27709; "Texas Institute for Discovery Education in Science, College of Natural \\ Sciences, University of Texas, Austin, TX 78712; "Department of Biochemistry \& Molecular Biology, \\ University of Georgia, Athens, GA 30602
}

\begin{abstract}
Course-based undergraduate research experiences (CUREs) provide a promising avenue to attract a larger and more diverse group of students into research careers. CUREs are thought to be distinctive in offering students opportunities to make discoveries, collaborate, engage in iterative work, and develop a sense of ownership of their lab course work. Yet how these elements affect students' intentions to pursue research-related careers remain unexplored. To address this knowledge gap, we collected data on three design features thought to be distinctive of CUREs (discovery, iteration, collaboration) and on students' levels of ownership and career intentions from $\sim \mathbf{8 0 0}$ undergraduates who had completed CURE or inquiry courses, including courses from the Freshman Research Initiative (FRI), which has a demonstrated positive effect on student retention in college and in science, technology, engineering, and mathematics. We used structural equation modeling to test relationships among the design features and student ownership and career intentions. We found that discovery, iteration, and collaboration had small but significant effects on students' intentions; these effects were fully mediated by student ownership. Students in FRI courses reported significantly higher levels of discovery, iteration, and ownership than students in other CUREs. FRI research courses alone had a significant effect on students' career intentions.
\end{abstract}

\section{INTRODUCTION}

The 2012 President's Council of Advisors on Science and Technology (Olson and Riordan, 2012) indicated that the United States needs to produce one million more college graduates in science, technology, engineering, and mathematics (STEM) to meet workforce demands in the coming decade. Life sciences are a particularly promising target for expanding and diversifying the STEM workforce because life science majors comprise the largest and most diverse pool of beginning STEM bachelor's students (Chen, 2013). Furthermore, workforce projections emphasize that the life sciences are areas of need (e.g., tailored therapies, synthetic biology, cognitive neuroscience, population health; National Research Council, 2011) and that bachelor's-level research and analytical positions have grown much faster than the rest of the biopharmaceutical industry (e.g., MassBioEd, 2016). However, undergraduate life science education faces a unique challenge. The majority of undergraduates enter biology degree
James Hewlett, Monitoring Editor Submitted July 26, 2017; Revised December 11, 2017; Accepted February 8, 2018

CBE Life Sci Educ June 1, 2018 17:ar20

DOI:10.1187/cbe.17-07-0141

*Address correspondence to: Erin L. Dolan (eldolan@uga.edu)

(C) 2018 L. A. Corwin et al. CBE-Life Sciences Education (C) 2018 The American Society for Cell Biology. This article is distributed by The American Society for Cell Biology under license from the author(s). It is available to the public under an Attribution-Noncommercial-Share Alike 3.0 Unported Creative Commons License (http:// creativecommons.org/licenses/by-nc-sa/3.0) "ASCB ${ }^{\circledR}$ " and "The American Society for Cell Biology ${ }^{\circledR "}$ are registered trademarks of The American Society for Cell Biology. 
programs intending to pursue clinical careers (physicians, pharmacists, etc.; Sadler et al., 2012), rather than research careers.

Course-based undergraduate research experiences (CUREs), which are courses that involve all enrolled students in addressing a research question or problem, provide an encouraging avenue to attract a larger and more diverse group of students in research (Wei and Woodin, 2011; Auchincloss et al., 2014; Bangera and Brownell, 2014). CUREs offered early in students' undergraduate careers are thought to be particularly advantageous because they have greater potential to influence students' academic and career trajectories (Harrison et al., 2011; Jordan et al., 2014). Students who participate in CUREs report many of the same positive outcomes as students who participate in apprenticeship-style undergraduate research experiences (UREs), such as increased knowledge, improved research skills, greater confidence in their ability to do science research, and greater clarity regarding their career choices (reviewed in Corwin et al., 2015a). In addition, at least one study shows that CUREs can help to retain students in college and in STEM (Rodenbusch et al., 2016). The three-semester CURE program that was the subject of this study, called the Freshman Research Initiative (FRI), engages students in designing, conducting, interpreting, and reporting their own inquiries (first-semester "inquiry course") and in research projects related to faculty members' ongoing research (second- and third-semester "research courses"; for details, see Beckham et al., 2015; Rodenbusch et al., 2016). However, the specific features of FRI or of CUREs in general that lead to positive student outcomes remain largely unidentified (Dolan, 2016).

In our prior work, we found that CUREs offer greater opportunities than traditional lab courses for students to make discoveries that are relevant to the broader scientific community and to engage in iterative work, including revising work based on feedback, collecting additional data, and repeating work as part of troubleshooting, problem solving, and confirming findings (Corwin et al., 2015b). We also found that CUREs engage students in collaborative work, but this was observed in both CUREs and traditional lab courses. Hanauer and colleagues determined that CURE students develop a greater level of ownership of their projects than students in traditional lab courses or in research internships and that students who reported greater ownership also reported greater intentions to continue in science (Hanauer et al., 2012; Hanauer and Dolan, 2014).

Here, we sought to understand how CUREs function to influence students' career paths. Specifically, we examined the influence of design features of CUREs (discovery, iteration, collaboration) on students' sense of ownership of their course work and their intentions to pursue a science research-related career. Directly relating course design features to student outcomes is an important first step toward determining how to design CUREs to maximize their effectiveness for students. To accomplish this, we used structural equation modeling (SEM) to test the hypothesis that students whose courses afforded greater opportunities to make discoveries, engage in iterative work, and collaborate would report a greater sense of ownership that explained changes in their intentions to pursue a science research-related career. We then characterized how these design features and outcomes varied among a national sample of CUREs in comparison with a group of CUREs known to increase student retention (FRI research courses) and a set of inquiry courses (FRI inquiry courses). This cross-course comparison is an important next step in determining how to tailor the design of CUREs to foster student interest in research careers.

\section{METHODS}

This study was reviewed and determined to be exempt by the Institutional Review Board at University of Texas, Austin (UT Austin; protocols \#2014-11-0051 and \#2014-11-0101).

\section{Participants}

We recruited students to participate in this study in Spring 2015 through three main avenues. We recruited FRI students through email invitations and three reminders distributed to all students who completed the relevant FRI courses at UT Austin in Fall 2014. We recruited students outside FRI through in-person announcements to instructors attending 2014 national meetings of the American Biology Laboratory Educators and the National Association of Biology Teachers and via email invitations to the listserv of CUREnet (https://curenet.cns.utexas .edu), a network of CURE instructors and programs. Interested instructors provided their email addresses, and we either sent the email invitations and reminders to them to distribute to their students or they gave us student email addresses and we sent invitations and reminders directly.

We invited a total of $\sim 2100$ undergraduate students to participate in the study: $~ 400$ from FRI inquiry courses, $\sim 600$ from the FRI research courses, and $\sim 100$ from a variety of courses at other institutions across the country. Of those invited, 836 completed the study: 147 in the FRI inquiry courses, 280 in the FRI research courses, and 409 students enrolled in 23 courses at other institutions across the country. The demographics of the participants are reported in Table 1 . The non-FRI students were drawn from diverse course types, including CUREs, inquiry courses, and traditional labs. We deliberately recruited students from courses of varying types so that their course design features were also likely to vary. Institution type (doctoral university, master's college or university, baccalaureate college: arts and science focus, associate's college) and course type (CURE, non-CURE, unclassified) of participants are reported in Table 2. We do not report response rates, because we cannot be sure of the number of students enrolled in each course. We determined institution type using the public 2015 Carnegie Institutional Classifications (IUCPR, 2015). We determined course type according to the procedure outlined in CrossCourse Comparison later in this section.

\section{Measures}

We surveyed students about the design features of their lab courses and their sense of ownership of their lab work at the end of their courses. We also surveyed students about their intentions to pursue a science research-related career before and following their courses. In the following sections, we describe the specific measures we used. All scales can be found in the Supplemental Material.

Discovery, Iteration, and Collaboration. We used the 17-item Laboratory Course Assessment Survey (LCAS; Corwin et al., 2015b), which asks students to rate their level of agreement that they were expected to engage in relevant discovery (five 
TABLE 1. Student demographic information

\begin{tabular}{lccc}
\hline & $\begin{array}{c}\text { Total study } \\
\text { sample }\end{array}$ & $\begin{array}{c}\text { FRI } \\
\text { sample }\end{array}$ & $\begin{array}{c}\text { External } \\
\text { sample }\end{array}$ \\
\hline Sample size $^{\mathrm{a}}$ & 836 & 427 & 409 \\
Male & 307 & 168 & 139 \\
Female & 517 & 251 & 266 \\
Other & 2 & 0 & 2 \\
No response & 2 & 8 & 2 \\
Hispanic/Latino(a) & 106 & 74 & 32 \\
Not Hispanic/Latino(a) & 693 & 333 & 360 \\
No response & 29 & 20 & 17 \\
White & 485 & 192 & 293 \\
Black & 39 & 15 & 24 \\
Asian & 225 & 153 & 72 \\
Multiracial & 21 & 21 & $0^{\mathrm{b}}$ \\
Other & 32 & 25 & 7 \\
Not reported & 26 & 21 & 13 \\
\hline
\end{tabular}

${ }^{a}$ Numbers reported represent total numbers of participants after data cleaning and removal of participants who did not fully complete the survey or selected to have their data removed from the data set.

${ }^{b}$ External participants were not given the opportunity to select more than one race.

items with six responses ranging from "strongly disagree" to "strongly agree") and were given time to do iterative work (six items with six responses ranging from "strongly disagree" to "strongly agree"), as well as how often they were encouraged to collaborate (six items with response options of "weekly," "monthly," "one or two times," and "never") in their lab courses.

Ownership. We used the 16-item Project Ownership Survey (Hanauer and Dolan, 2014). The Cognitive Ownership subscale includes 10 items that ask students to rate on a five-point scale their level of agreement that they had intellectual responsibility for their lab work (e.g., "I faced challenges that I managed to overcome in completing my project," with five responses ranging from "strongly disagree" to "strongly agree") and that their projects were important, interesting, and intellectually engaging (e.g., "The research question I worked on was important to me"). The Emotional Ownership subscale includes six items that ask students to rate on a five-point scale their strength of emotion about their lab work (e.g., "To what extent does delighted describe your experience of the laboratory course?," with five responses ranging from "very slightly" to "very strongly").
Intentions. We used two items to gauge students' intentions to pursue a science-related research career, one focused on their current intentions ("To what extent do you intend to pursue a science-related research career?") and one that was retrospective ("Prior to this course, to what extent did you intend to pursue a science-related research career?"). This measure has been used by others to gauge students' level of integration into the scientific community and has been found to correlate significantly with behaviors associated with pursuing a scientific career (Estrada et al., 2011). The response options ranged from 0 (definitely will not) to 10 (definitely will). For students in FRI courses, both the current and retrospective questions were administered at the same time (i.e., postcourse), because we were unable to collect precourse data for these students. For students outside FRI, the current intentions question was administered both pre- and postcourse. The precourse rating of students' intentions was subtracted from the postcourse rating to determine the change in students' intentions over the course.

\section{Data Analysis}

Hypothesis Testing. We were interested in determining whether students whose courses afforded greater opportunities to make discoveries, engage in iterative work, and collaborate would report a greater sense of ownership that explained changes in their intentions to pursue a science research-related career. Thus, we chose to use SEM to examine relationships among course design features of discovery, iteration, and collaboration, and students' levels of cognitive and emotional ownership and their intentions to persist in a science researchrelated career. SEM is a statistical linear modeling method that allows for testing of hypothesized relationships between latent variables (Kline, 2015). There are two major components to SEM: the measurement model and the structural model. The measurement model helps to properly define the latent variables (i.e., constructs represented by items) in terms of the observed variables (i.e., item responses). The structural model specifies the relationships between the latent variables, thereby testing proposed hypotheses. We focus here on structural model testing, because our primary interest is in testing our hypothesis. We describe the measurement model testing in the Supplemental Material, including modifications to improve measurement model fit and analytic adjustments to account for the sampling of students nested within different classrooms.

We used the entire sample $(N=836)$ to examine two structural models (Figure 1) to determine whether students' perceptions of their course design predicted their levels of ownership and postcourse intentions to pursue a science research-related career. One model (1A) included only indirect effects of course

TABLE 2. External institution types and number of courses

\begin{tabular}{lccccc}
\hline & Students surveyed & Courses surveyed & CUREs & Non-CURE & Unclassified $^{\text {a }}$ \\
\hline Sample size $^{\mathrm{b}}$ & 409 & 23 & 6 & 9 & 8 \\
Doctoral universities & 222 & 4 & 0 & 2 & 2 \\
Master's colleges/universities & 26 & 4 & 1 & 1 & 2 \\
Baccalaureate colleges & 144 & 13 & 4 & 5 & 4 \\
Associate's colleges & 17 & 2 & 1 & 1 & 0 \\
\hline
\end{tabular}

a"Unclassified" refers to courses for which data used for classification were not provided.

${ }^{\mathrm{b}}$ Numbers reported represent total numbers of participants after data cleaning and removal of participants who did not complete the survey or selected to have their data removed from the data set. 



FIGURE 1. Relationships among course design features, levels of student ownership, and student intentions to pursue a science researchrelated career. We tested four structural models to identify and characterize relationships among course design features, student ownership, and students' career intentions. All significant relationships are solid bold; nonsignificant relationships are dashed. Relationships between predictors and outcomes are in black; correlations among predictors and between mediators are in blue. We found that collaboration positively predicted both cognitive and emotional ownership, discovery positively predicted cognitive but not emotional ownership, and iteration positively predicted both cognitive and emotional ownership, having the largest collective effect of the three design features. Cognitive and emotional ownership both positively predicted students' career intentions. Altogether, course design features and ownership explained 0.1 of the variance in students' career intentions ( $R^{2}=0.11$ for models $1 \mathrm{~A}$ and $\left.1 \mathrm{~B}\right)$. Including students' prior career intentions in the model explained almost half the variance in students' career intentions $\left(R^{2}=0.45\right.$ for model $2 A, R^{2}=0.48$ for model 2B). Including direct effects of design features on students' career intentions (models $1 \mathrm{~B}$ and 2B) did not improve model fit significantly over the more parsimonious models with indirect effects alone (models $1 \mathrm{~A}$ and $2 \mathrm{~A}$ ).

design features on students' career intentions, and the other model (1B) included both direct and indirect effects. If we observed only indirect effects, we could infer that course design features affect students' career intentions solely by affecting their sense of ownership. If we observed both direct and indirect effects, we could infer that course design features affect student ownership, which in turn affects their career intentions, as well as affecting their career intentions in ways not reflected in their sense of ownership. We tested two additional models (models $2 \mathrm{~A}$ and $\mathrm{B}$ ) that also included prior intention to pursue a science research-related career as a predictor. For both pairs of models, we conducted a test of the difference of the chi-square statistics of nested models. If adding regression parameters (i.e., relationships between any two of the following variables: course design features, ownership, and career intentions) reduced the chisquare value, we tested to see whether the reduction was statistically significant. If so, we kept the path in the model, because this indicated that including the relationship provided a better fit to the observed data and explained a significant amount of variance. If the chi-square test was not significant, we opted for the more parsimonious model, as it explained the data just as well. We adjusted the chi-square test to account for the use of the maximum likelihood robust estimator (Satorra and Bentler, 2001).

Cross-Course Comparison. We compared three course types: FRI inquiry courses $(n=147)$, FRI research courses $(n=280)$, and "other CUREs" $(n=241)$. FRI inquiry courses are the first course in the FRI curriculum and have a stated goal of engaging students in their own scientific inquiries (Beckham et al., 2015; Brownell and Kloser, 2015). FRI research courses are the second and third courses in the FRI curriculum and have a stated goal of engaging students in faculty-mentored research. For the other CUREs, two authors (E.G. and M.S.) read course syllabi and laboratory manuals, rated them independently, and subsequently came to consensus on course ratings. Courses were determined to be CUREs if they included 1) a science research project that had the potential to 2) generate novel findings that were previously unknown to the students, instructors, and the broader scientific community and that had 3) importance 
outside the classroom. Only courses that met all three criteria were considered CUREs. In general, CUREs framed students' lab work in terms of addressing a central scientific question or reaching a particular scientific goal instead of as discrete exercises or scientific topics. For this analysis, we did not include courses that could not clearly be categorized (Table 2).

To compare the level of discovery, iteration, collaboration, and ownership afforded by the different courses, we first calculated factor scores for each variable, with the exception of career intentions, which was measured with a single item and for which we did not need to calculate a factor score. Factor scores are composite measures of a latent construct in which the observed response for a given item is weighted by the item's reliability in measuring that latent construct (for further details, see DiStefano et al., 2009). Because factor scores are a z-score metric with a mean of 0 and an SD of 1 , a factor score of 0 for a student means that the student's responses are at the mean of that latent variable (see the Supplemental Material for details).

We then regressed course type as an unordered categorical variable on each of the five factor scores (i.e., discovery, iteration, collaboration, cognitive ownership, emotional ownership) and also on students' postcourse career intentions. We used the other CUREs as the baseline for comparison. Because this involved examining six different regression models, we used a Bonferroni correction to help control for our experiment-wise type I error rate, resulting in a cutoff value of $p=(0.05 / 6)=$ 0.008 . We also generated density plots to allow for visual comparisons of the distribution of factor scores in each of the course types. Much like histograms, density plots allow the visualization of the distribution of data over an observed continuous interval, but their shape is smoothed via kernel smoothing. This smoothing allows for visualizations of the data without having to choose the number of bins used in a histogram and produces a better visualization of the full distribution of the data. Integrating over a density function results in a value of 1 , regardless of the number of points (i.e., observations) that are used to create the density plot. This allows for the comparison of distributions across groups of unequal sizes, as was in the case in this study. Each of the density plots (except change in intention) has the normed factor score along $x$-axis, so $x$-axis units are to be interpreted as SDs away from the mean. Higher peaks in a density function represent a greater proportion of the sample in that specific area of $x$-axis, just like a tall histogram bin that contains a large number of observations. The absolute numbers of the $y$-axis do not provide much utility beyond relative comparisons within the same plot (both within and across groups), and thus have been removed from the graphs to prevent any misinterpretation.

\section{RESULTS}

Relationships between Course Design, Student Ownership, and Student Career Intentions

Given our interest in the influence of CUREs on students' career pursuits, we used SEM to determine whether course design features related to students' postcourse career intentions. We also tested whether students' cognitive and emotional ownership mediated the observed relationships between course features and students' career intentions, in other words, whether course features influenced students' career intentions by developing their sense of ownership (indirect effects) or through some other mechanism acting directly on intentions (direct effects). Figure 1 depicts four models we tested. Model 1A includes only indirect effects of course design features (predictors) on students' postcourse career intentions (outcome), with students' cognitive and emotional ownership as mediators of these relationships. Model 1B includes both direct and indirect effects. Models $2 \mathrm{~A}$ and $2 \mathrm{~B}$ are the same as models $1 \mathrm{~A}$ and $1 \mathrm{~B}$, but they include students' precourse career intentions as an additional predictor of changes in students' career intentions. For all models, solid paths indicate statistically significant relationships, while dashed paths are not statistically significant. Black paths indicate what we hypothesize to be predictive relationships, and blue paths indicate correlations among the predictors (i.e., collaboration, discovery, iteration) and between the mediators (i.e., cognitive ownership and emotional ownership). All numerical values are standardized correlation coefficients $(\beta)$ on a scale of -1 to +1 to facilitate comparisons of the influences of the predictors and the mediators on the outcome.

We found that all three course design features (collaboration, discovery, iteration) were significantly and positively related to students' cognitive ownership of their course work $(\beta=0.26,0.26,0.31$, respectively; model $1 \mathrm{~A})$. Each design feature appeared to explain a similar amount of the variance in students' cognitive ownership, suggesting that all three features are important for achieving this short-term outcome. In contrast, collaboration and iteration were significantly and positively related to students' emotional ownership of their course work ( $\beta=0.17$ and 0.37 , respectively), while discovery was not. Iteration explained more of the variation in students' emotional ownership than collaboration (i.e., larger $\beta$ ). Students' cognitive and emotional ownership were both positively and significantly related to students' career intentions, with cognitive ownership explaining slightly more of the variation in students' career intentions $(\beta=0.21)$ compared with their emotional ownership $(\beta=0.14)$. Altogether, the model explained only a small amount of the variance in students' career intentions $\left(R^{2}=0.11\right.$, or $\left.11 \%\right)$.

We also tested model 1B, which includes both direct effects of course features on students' career intentions and indirect effects via ownership. By testing this model, we could determine whether collaboration, discovery, and iteration influence students' career intentions in ways that are independent of their levels of ownership. We found that including these three direct paths from course design features to changes in students' intentions did not significantly improve the fit of the model $\left(\chi^{2}(3)=\right.$ $2.42, p=0.49)$. In addition, none of the direct relationships between course design features and students' career intentions were significant (all dashed lines). This means that any effects that course design features had on students' intentions to pursue a science research-related career were fully mediated by ownership. On the basis of this result, we can infer that the courses in our sample that offered greater opportunities to make discoveries, more time for iteration, and more opportunities to collaborate resulted in students developing greater sense of ownership of their lab work, which resulted in greater intentions to pursue a science research-related career.

We tested two additional models (Figure 1, models 2A and 2B) to gain insight into the extent to which students' career intentions before the course account for their postcourse intent. We found that students' precourse career intentions explained most but not all of the variance in a student's postcourse 
TABLE 3. Comparison group descriptive statistics

\begin{tabular}{|c|c|c|c|c|c|c|}
\hline \multirow[b]{3}{*}{ Course type } & \multicolumn{6}{|c|}{ Scales $^{\mathrm{a}}$} \\
\hline & \multicolumn{2}{|c|}{ Discovery } & \multicolumn{2}{|c|}{ Iteration } & \multicolumn{2}{|c|}{ Collaboration } \\
\hline & Median & Mean (SD) & Median & Mean (SD) & Median & Mean (SD) \\
\hline Other CURES & 0.10 & $-0.21(0.98)$ & -0.08 & $-0.20(0.78)$ & 0.21 & $0.03(0.34)$ \\
\hline FRI research & 0.43 & $0.33(0.68)$ & 0.39 & $0.30(0.66)$ & 0.10 & $0.01(0.26)$ \\
\hline \multirow[t]{2}{*}{ FRI inquiry } & 0.42 & $0.31(0.74)$ & 0.23 & $0.12(0.66)$ & -0.08 & $-0.09(0.27)$ \\
\hline & \multicolumn{2}{|c|}{ Cognitive Ownership } & \multicolumn{2}{|c|}{ Emotional Ownership } & \multicolumn{2}{|c|}{ Change in Intention } \\
\hline Course type & Median & Mean (SD) & Median & Mean (SD) & Median & Mean (SD) \\
\hline Other CURES & -0.02 & $-0.21(0.73)$ & -0.11 & $-0.25(1.22)$ & 0 & $0.00(2.91)$ \\
\hline FRI research & 0.29 & $0.24(0.57)$ & 0.28 & $0.24(1.12)$ & 1 & $1.05(2.30)$ \\
\hline FRI inquiry & 0.25 & $0.18(0.60)$ & 0.35 & $0.22(1.12)$ & 0 & $0.55(1.94)$ \\
\hline
\end{tabular}

aalues for all scales reflect factor scores, except Change in Intention, which reflects the difference in pre- versus postcourse intentions to pursue a science researchrelated career.

intentions (Figure $1 ; \beta=\sim 0.6$ ). This is not surprising given that STEM career intentions as early as middle school predict longterm actions and future pursuit of STEM majors (Tai et al., 2006). These models demonstrate that the effect of course design features on student ownership and career intentions is robust (i.e., little if any change in $\beta$ for each relationship) even when students' precourse career intentions are taken into account (see the Supplemental Material for details about pre- to postcourse intentions).

\section{Cross-Course Comparison}

Given that our analyses showed that CURE design features were positively related to students' ownership and career intentions, we sought to determine how these features compared among FRI research courses, FRI inquiry courses, and other CUREs (i.e., research courses at institutions other than UT Austin). Our sample included six other CUREs courses at six different institutions, 19 FRI research courses, and five FRI inquiry courses (Table 2). Descriptive statistics for the factor scores for each design feature, students' cognitive and emotional ownership, and students' changes in career intentions by course type are provided in Table 3.

Discovery. For the most part, students in all three course types rated opportunities for discovery high, as evidenced by the large proportion of the density plots falling above 0 for all course types (Figure 2A). This finding is consistent with the idea that these courses are intended to engage students in doing investigations with unknown outcomes. Students in FRI research and inquiry courses report that their courses offer greater opportunities for discovery compared with students in other CUREs (Table 3). This difference is significant but small ( $p<0.001$; adjusted $R^{2}=0.087$ ) between other CUREs (factor score $=-0.21$ ) and both FRI research courses and FRI inquiry courses (factor scores $=+0.33$ and +0.31 , respectively). Responses of students from other CUREs also spanned a broader range of discovery than responses of students in FRI research and inquiry courses (i.e., the curve has longer tails). This result indicates that students in the other CUREs varied more in whether they thought they had opportunities to make discoveries. In contrast, students in FRI research and inquiry courses reported similar levels of discovery, which suggests that students may perceive the inquiries they design as offering the same potential for discovery as research projects more directly related to faculty members' ongoing research (i.e., CUREs).

Iteration. Students in FRI research and inquiry courses rated their courses high on the iteration scale, reflected in the highest densities for these courses falling above 0 (Figure 2B) and positive mean values (Table 3). Students in FRI research courses reported the highest levels of iteration (factor score $=+0.30$ ), followed by students in FRI inquiry courses (factor score = +0.12 ), with the lowest levels of iteration reported by students in other CUREs (factor score $=-0.20$ ). Both the FRI research and inquiry course iteration values were significantly higher than the value for other CUREs $\left(p<0.001\right.$; adjusted $R^{2}=$ 0.087). Iteration values in FRI research courses were significantly higher than in FRI inquiry courses, but by only a very small margin $\left(p<0.006\right.$; adjusted $\left.R^{2}=0.015\right)$. These results suggest that FRI courses, especially FRI research courses, may be unique compared with other CUREs in affording time for students to repeat aspects of their work and engage in troubleshooting. This result may reflect the fact that FRI inquiry courses are one semester long and FRI research courses are one to two semesters long, while CUREs described elsewhere vary widely in their duration (Dolan, 2016).

Collaboration. Students in other CUREs reported the highest levels of collaboration (factor score $=+0.03$; Figure $2 \mathrm{C}$ and Table 3), followed by students in FRI research courses (factor score $=+0.01)$, with the lowest levels of collaboration reported by FRI inquiry course students (-0.09). The levels of collaboration reported by students in other CUREs and FRI research courses were significantly higher than the value for FRI inquiry courses, although course type explained only a very small proportion of the variance in collaboration $(p=0.004$; adjusted $\left.R^{2}=0.025\right)$. This may reflect the fact that students in FRI inquiry courses work on separate projects in pairs or small groups, while students in FRI research courses and in many other CUREs engage in class-wide collaboration toward a common goal.

Cognitive Ownership. Students in FRI research and inquiry courses reported similar levels of cognitive ownership (factor scores $=+0.24$ and +0.18 , respectively; Figure 2D and Table 3 ) 

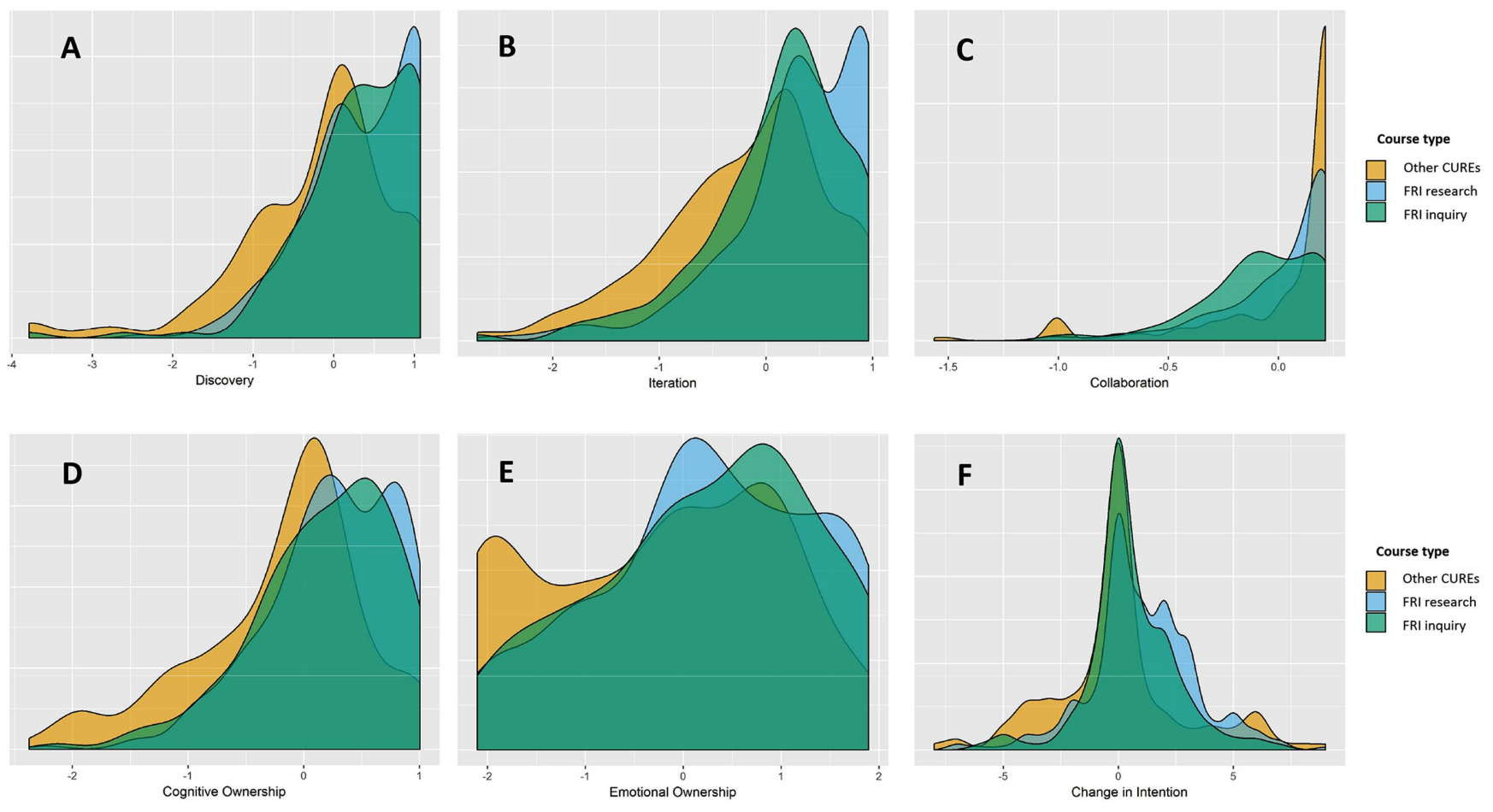

FIGURE 2. Comparison of course design features, levels of ownership, and shifts in career intentions among students in FRI research courses, FRI inquiry courses, and other CUREs. Each panel features three density plots, one for each course type, which are smoothed histograms of the factor scores for each construct of interest. The proportion under the curve that falls above 0 indicates high ratings from students for the course type. The degree of curve overlap indicates how similar the course types were for each construct; broad curves indicate high variability among student responses, while narrow peaks indicate lower variability.

and significantly higher cognitive ownership than students in other CUREs (factor score $=-0.21 ; p<0.001$; adjusted $R^{2}=$ 0.09). Again, this result may be due to the fact that FRI research and inquiry courses are longer in duration than other CUREs, which allows more time for ownership to develop. It is important to note, however, that duration is not likely to be the sole driver of the development of a sense of ownership, because previous research revealed differences in ownership across lab or field learning experiences of similar duration (Hanauer et al., 2012).

Emotional Ownership. Students in FRI research and inquiry courses also reported similar levels of emotional ownership (factor scores $=+0.24$ and +0.22 , respectively; Figure $2 \mathrm{E}$ and Table 3 ) and significantly higher emotional ownership than students in other CUREs (factor score $=-0.25 ; p<0.001$; adjusted $R^{2}=$ 0.04). There is notably more variance in emotional ownership within all course types, as seen by the density plots widely spanning the entire $x$-axis. This result may reflect differences among students and how they respond to their lab learning experiences or differences among courses within each course type.

Intentions. Students in FRI research courses reported significant, positive changes in their intentions to persist in science research-related careers in comparison with students in other CUREs (mean change $=+1.05, \mathrm{SD}=2.30$; Figure $2 \mathrm{~F}$ and Table $3)$. Students in FRI inquiry courses also reported a positive shift (mean change $=+0.55, \mathrm{SD}=1.94$ ), but it was not significantly different from that of students in FRI research courses or other CUREs, perhaps due to the very small proportion of the variance in students' intentions that could be attributed to course type $\left(p=0.05\right.$; adjusted $\left.R^{2}=0.03\right)$.

\section{Limitations}

We draw attention to several issues that limit what can be inferred from our results. First, although we made sincere attempts to recruit students representing a range of course types, especially CURE courses, the number of courses represented in our sample is limited, and not all students in each course chose to participate in the study. Both of these issues raise questions about the generalizability of the findings from other CUREs and whether our sample may be subject to self-selection bias. Thus, we urge caution in making general statements about all CUREs based on findings from this study. Future research should draw from a larger sample of CUREs and, ideally, analyze the data in a way that accounts for their nested nature (i.e., students within courses, courses within institutions, or institution types). We chose to analyze this data set at the student level given our interest in examining the effects of course design on students' career intentions, which is a student-level variable.

Second, we measured student intentions to persist in a science research-related career, which limits our findings in two ways. First, career intentions are not as reliable a measure of career pursuit as direct tracking of students. However, we are collecting data over time from the FRI students who participated 
in this study and, ultimately, we will be able to determine the extent to which their reported intentions predict their actual career pursuits. It is also important to note that a student's educational aspirations are one of the strongest predictors of subsequent enrollment in a graduate degree program (Heller, 2001; Mullen et al., 2003; Walpole, 2003; Nevill and Chen, 2007). Second, the items we used to measure career intentions only relate to students' intentions to pursue a science researchrelated career. This served our interests in studying CUREs as a context for student learning and development related to doing research and in comparing our findings with results from the study of other undergraduate research experiences (e.g., Estrada et al., 2011). Yet students in this study could complete science degrees and pursue science-related career paths that they might not characterize as research related, which may or may not be reflected in their response to the intentions items we used.

Finally, we treated all students as a single group for our analyses. Our sample did not include sufficient numbers of students of different genders, races, or ethnicities within each course type to determine whether students' experiences differed based on their personal characteristics. Prior research has shown that research experiences influence the academic and career trajectories of students of color (Estrada et al., 2011; Schultz et al., 2011). The few studies that have included sufficient numbers of students from underrepresented and well-represented groups have not found differential effects of research experiences (e.g., Eagan et al., 2013; Rodenbusch et al., 2016). Yet in-depth examination of how underrepresented minority students experience research indicates that the mechanism by which these experiences are influential may be distinctive (Carlone and Johnson, 2007; Hurtado et al., 2008, 2011). Similar studies should be conducted in the context of CUREs to gain insight into how different groups of students may or may not differ in their experiences and outcomes with CURE instruction.

\section{DISCUSSION \\ Mechanism}

We used SEM to gain insight into the mechanism by which lab courses may be influencing students' career trajectories. Our results show that all three design features (discovery, iteration, collaboration) positively predicted students' cognitive ownership of their course work, which in turn predicted positive changes in their intentions to pursue a science research-related career. These results further support the hypothesis that discovery, iteration, and collaboration are important elements of the design of CUREs that intend to attract or retain students in research-related career paths (Auchincloss et al., 2014; Corwin et al., 2015b).

Collaboration and iteration, but not discovery, predicted students' emotional ownership of their course work, which also predicted positive shifts in students' career intentions. The lack of influence of discovery is somewhat surprising, because much of the conversation around what makes CUREs unique and powerful for students has centered on the opportunity for students to engage in "real" science that is of interest to the scientific community and can produce publishable results (Hatfull et al., 2006; Wiley and Stover, 2014). These results may reflect that students differ in how excited they are to make discoveries or to pursue their own line of inquiry (see wide variation in students' emotional ownership in Figure 2E). In addition, students in some courses may have made discoveries or found unanticipated results and thus experienced excitement and surprise, while others did not. This result complements work from Wiley and Stover (2014) that indicates that opportunities to publish (i.e., report discoveries by coauthoring scientific papers) may be less critical for students than was assumed when CUREs were first developed.

By comparing the standardized correlation coefficients $(\beta)$ between the course design features and ownership in the four models presented here (Figure 1), we can conclude that iterative work, such as revising work to account for errors or collecting and analyzing additional data to confirm or further test hypotheses, had the strongest collective effect on students' sense of ownership. This result suggests that the power of CUREs may be in providing a relatively low-risk environment for students to fail, troubleshoot, problem solve, and make progress. This result also provides preliminary evidence that the design of CUREs should favor allowing time and latitude for students to engage in iterative work, even at the risk of reducing the likelihood that students will make publishable discoveries.

On the basis of the $R^{2}$ values for models $1 \mathrm{~A}$ and $1 \mathrm{~B}$, we conclude that course design features and students' sense of ownership explain only a modest amount of the variance in students' career intentions $(-11 \%)$. Small effects are not surprising, given the complexity of the entire undergraduate experience, and even small differences are associated with students' long-term persistence in science (e.g., Estrada et al., 2011). Yet these results indicate that there are other factors both within and beyond CUREs that are leading to shifts in students' career intentions on a semester timescale (i.e., the window of data collection in this study). For example, CUREs appear to vary in the extent to which students have liberty to set the direction of their research and to take intellectual responsibility for aspects of the research, such as determining which research questions to pursue and making decisions about how to troubleshoot and how to analyze or interpret data (Linn et al., 2015; Dolan, 2016; Gentile et al., 2017). Future research should explore more deeply how students experience different forms of lab instruction, for example, through classroom observations and student interviews throughout instruction, to better understand the unique affordances and constraints of inquiry and research instruction at the undergraduate level.

The effects of discovery, iteration, and collaboration on students' career intentions were entirely mediated by students' sense of ownership of their projects. Future research should examine whether this result is replicable. If so, instructors could collect data on the course design features and student ownership of their CUREs, use the results to determine whether their CUREs are falling short of desired levels, and make adjustments to their course designs accordingly. Future work should be done to improve the quality of the project ownership survey (see the Supplemental Material for details), such as addressing the correlating errors of pairs of items (i.e., 1 and 2, 6 and 7, 9 and 10) and adding items that more fully capture what appear to be two factors of emotional ownership: enjoyment (items 11, 12,13 ) and surprise (items 14, 15, 16). This would require additional qualitative work to more fully explore the emotions 
that students develop (or not) related to their research projects and additional testing of item wording to ensure factor loadings reflect meaningful relationships as much as possible rather than item syntax or grammar. In addition, it is important to note that our outcome of interest in this study was limited to students' research career intentions. Lab courses that involve students in discovery, iteration, and collaboration are likely to influence students in other meaningful ways, such as by fostering student understanding of the nature and practices of science and improving students' beliefs about the value of science research even if they do not choose to pursue it as a career path.

\section{Cross-Course Comparison}

Our SEM results indicate that the course design features of discovery, iteration, and collaboration influence students' ownership of their lab course work, which in turn can influence their career intentions. Thus, it becomes important to characterize whether and to what extent these design features are present in courses called "CUREs" and also in other lab courses that involve students in scientific practices, such as inquiry courses. We found that FRI research courses, FRI inquiry courses, and other CUREs differed in affording students opportunities for discovery and iteration and in their influence on students' sense of ownership. Students in FRI research courses report the highest levels of discovery, iteration, and ownership, followed by students in FRI inquiry courses and other CUREs. As noted earlier, FRI research courses can span up to two semesters, while other CUREs (reviewed in Dolan, 2016) vary widely in their duration, from a single lab session to multiple quarters or semesters. We did not control for duration of each learning experience in this study, because the data for the duration of the other CUREs was not available. Thus, the differences we observed in the levels of discovery, iteration, and ownership may be the result of time students spent doing the work. Future research should explore the influence of duration of CURE or inquiry experiences on students' perceptions of whether their courses afford opportunities for discovery and iteration and the extent to which students develop ownership of their projects. Future research should also explore whether duration moderates the relationships among course design features, ownership, and career intentions.

FRI research and inquiry courses were not significantly different in terms of their other design features (discovery, iteration) or in students' development of cognitive and emotional ownership. The results suggest that semester-long inquiry courses may have several of the same features as CUREs and result in similar levels of student ownership. However, students in FRI inquiry courses reported lower levels of collaboration than students in research courses. This result likely reflects the nature of the FRI inquiry course, in which students work alone or in pairs to design and conduct their own inquiries (Beckham et al., 2015; Rodenbusch et al., 2016), rather than addressing a research question or problem related to a faculty member's ongoing research.

FRI research courses, but not FRI inquiry courses or other CUREs, had a significant effect on students' career intentions. Again, this result may be due to the amount of time students spend pursuing a line of research or inquiry-the more time they spend, the more likely they are to be interested in research and to continue in a research-related educational or career path. Hidi and Renninger (2006) put forth a four-phase model of interest development over time that may be useful for understanding how student interest in research develops into career pursuits. Specifically, short-duration CUREs may be useful for making students aware of research, introducing them to scientific practices, and sparking an initial interest (i.e., situational interest). Longer-duration CUREs may offer a more sustained experience through which students explore more deeply what it is like to do research (i.e., maintained situational interest). Students who remain interested in research may then seek out additional research experiences themselves (i.e., individual interest), most likely in the form of internships in faculty members' research groups. Finally, students who remain interested will transition to charting their own paths involving further education and careers in science research (i.e., well-developed individual interest). Testing these ideas will require longitudinal research that characterizes how students' research career interests change during different types of research experiences and throughout their undergraduate experiences.

\section{Theoretical Perspectives}

The recent consensus report on undergraduate research experiences in STEM called for greater use of theories related to student learning and development in studies of UREs and CUREs (Gentile et al., 2017). In this study, we took a more grounded approach by observing how lab learning experiences differed and exploring how these differences relate to students' career intentions. On the basis of our results, we propose that future research on how CURE instruction influences students' career intentions make use of theories of motivation. For example, we observed positive relationships between courses that involved students in iterative work and students' cognitive and emotional ownership and their career intentions. It may be that students who engage in iterative work become more capable of mastering the work and thus more confident in their ability to do the work, which would increase their intentions to stay in science. This hypothesis is consistent with multiple theories of motivation (e.g., self-efficacy theory, expectancy-value theory, self-determination theory), which argue that people are intrinsically motivated when they believe they are competent (Ryan and Deci, 2000; Wigfield and Eccles, 2000; Wentzel and Miele, 2016).

We also observed positive relationships between courses that offered students opportunities to make discoveries and students' cognitive ownership and career intentions. Students who have opportunities to make discoveries may view their work as having broader utility and thus are more motivated to do it and to stay in science. This hypothesis is consistent with aspects of expectancy-value theory: that people are intrinsically motivated if they see value or purpose in their work (Wigfield and Eccles, 2000). We observed positive relationships between courses in which students collaborated and students' ownership and career intentions. Students who have opportunities to collaborate may enjoy the work more, which could positively influence their intentions to pursue research-related careers. This hypothesis is consistent with the self-determination theory of motivation, which postulates that people are intrinsically motivated by connecting in meaningful ways with others (Ryan and Deci, 2000). 
Finally, we found that the relationships between course design features and students' career intentions were all mediated by ownership. This result is also consistent with self-determination theory, which purports that people are intrinsically motivated when their need for autonomy is met (Ryan and Deci, 2000), resulting in a sense of ownership (Hanauer et al., 2012; Hanauer and Dolan, 2014). That said, the need for autonomy and thus ownership may be culturally bounded (Markus and Kitayama, 1991; Rudy et al., 2007), an issue that has yet to be explored in the context of UREs or CUREs. Future research should test these theories more directly to determine their utility for explaining how CUREs and research experiences in general influence students' career trajectories.

\section{ACKNOWLEDGMENTS}

We thank the students who participated in this study for their responses and their instructors for working with us to collect data. Support for this work was provided by a grant from the National Science Foundation (NSF DBI-1450729) and a grant from the Howard Hughes Medical Institute (HHMI \#52006958). The contents of this paper are solely the responsibility of the authors and do not necessarily represent the official views of NSF or HHMI.

\section{REFERENCES}

Auchincloss, L. C., Laursen, S. L., Branchaw, J. L., Eagan, K., Graham, M., Hanauer, D. I., ... Dolan, E. L. (2014). Assessment of course-based undergraduate research experiences: A meeting report. CBE-Life Sciences Education, 13(1), 29-40. https://doi.org/10.1187/cbe.14-01-0004

Bangera, G., \& Brownell, S. E. (2014). Course-based undergraduate research experiences can make scientific research more inclusive. CBE-Life Sciences Education, 13(4), 602-606. https://doi.org/10.1187/cbe.14-06 $-0099$

Beckham, J. T., Simmons, S., Stovall, G. M., \& Farre, J. (2015). The Freshman Research Initiative as a model for addressing shortages and disparities in STEM engagement. In Peterson, M. A., \& Rubinstein, Y. A. (Eds.), Directions for mathematics research experience for undergraduates (pp. 181-212). Singapore: World Scientific.

Brownell, S. E., \& Kloser, M. J. (2015). Toward a conceptual framework for measuring the effectiveness of course-based undergraduate research experiences in undergraduate biology. Studies in Higher Education, 40(3), 525-544. https://doi.org/10.1080/03075079.2015.1004234

Carlone, H. B., \& Johnson, A. (2007). Understanding the science experiences of successful women of color: Science identity as an analytic lens. Journal of Research in Science Teaching, 44(8), 1187-1218. https://doi.org/ 10.1002/tea.20237

Chen, X. (2013). STEM attrition: College students' paths into and out of STEM fields: Statistical analysis report (NCES 2014-001). Washington, DC: National Center for Education Statistics. Retrieved April 18, 2017, from https://eric.ed.gov/?id=ED544470

Corwin, L. A., Graham, M. J., \& Dolan, E. L. (2015a). Modeling course-based undergraduate research experiences: An agenda for future research and evaluation. CBE-Life Sciences Education, 14(1), es1. https://doi.org/ 10.1187/cbe.14-10-0167

Corwin, L. A., Runyon, C., Robinson, A., \& Dolan, E. L. (2015b). The Laboratory Course Assessment Survey: A tool to measure three dimensions of research-course design. CBE-Life Sciences Education, 14(4), ar37. https:// doi.org/10.1187/cbe.15-03-0073

DiStefano, C., Zhu, M., \& Mindrila, D. (2009). Understanding and using factor scores: Considerations for the applied researcher. Practical Assessment, Research \& Evaluation, 14(20), 1-11.

Dolan, E. L. (2016). Course-based undergraduate research experiences: Current knowledge and future directions. Washington, DC: National Research Council.
Eagan, M. K., Hurtado, S., Chang, M. J., Garcia, G. A., Herrera, F. A., \& Garibay, J. C. (2013). Making a difference in science education: The impact of undergraduate research programs. American Educational Research Journal, 50(4), 683-713. https://doi.org/10.3102/0002831213482038

Estrada, M., Woodcock, A., Hernandez, P. R., \& Schultz, W. P. (2011). Toward a model of social influence that explains minority student integration into the scientific community. Journal of Educational Psychology, 103(1), 206-222. https://doi.org/10.1037/a0020743

Gentile, J., Brenner, K., \& Stephens, A.( (2017). Undergraduate research experiences for STEM students: Successes, challenges, and opportunities Washington, DC: National Academies Press. Retrieved May 17, 2017, from www.nap.edu/catalog/24622/undergraduate-research-experiences -for-stem-students-successes-challenges-and-opportunities

Hanauer, D. I., \& Dolan, E. L. (2014). The Project Ownership Survey: Measuring differences in scientific inquiry experiences. CBE-Life Sciences Education, 13(1), 149-158. https://doi.org/10.1187/cbe.13-06-0123

Hanauer, D. I., Frederick, J., Fotinakes, B., \& Strobel, S. A. (2012). Linguistic analysis of project ownership for undergraduate research experiences. CBE-Life SCiences Education, 11(4), 378-385. https://doi.org/10.1187/cbe.12-04-0043

Harrison, M., Dunbar, D., Ratmansky, L., Boyd, K., \& Lopatto, D. (2011). Classroom-based science research at the introductory level: Changes in career choices and attitude. CBE-Life Sciences Education, 10(3), 279286. https://doi.org/10.1187/cbe.10-12-0151

Hatfull, G. F., Pedulla, M. L., Jacobs-Sera, D., Cichon, P. M., Foley, A., Ford, M. E., ... Hendrix, R. W. (2006). Exploring the mycobacteriophage metaproteome: Phage genomics as an educational platform. PLoS Genetics, 2(6), e92. https://doi.org/10.1371/journal.pgen.0020092

Heller, D. E. (2001). Debts and decisions: Student loans and their relationship to graduate school and career choice (New agenda series, vol. 3, no. 4). Indianapolis, IN: Lumina Foundation for Education. Retrieved June 28 2017, from https://eric.ed.gov/?id=ED453722

Hidi, S., \& Renninger, K. A. (2006). The four-phase model of interest development. Educational Psychologist, 41(2), 111-127. https://doi.org/10.1207/ s15326985ep4102_4

Hurtado, S., Cabrera, N. L., Lin, M. H., Arellano, L., \& Espinosa, L. L. (2008) Diversifying science: Underrepresented student experiences in structured research programs. Research in Higher Education, 50(2), 189-214 https://doi.org/10.1007/s11162-008-9114-7

Hurtado, S., Eagan, M. K., Tran, M. C., Newman, C. B., Chang, M. J., \& Velasco, P. (2011). "We do science here": Underrepresented students' interactions with faculty in different college contexts. Journal of Social Issues, 67(3), 553-579. https://doi.org/10.1111/j.1540-4560.2011.01714.x

IUCPR. (2015). The Carnegie Classification of Institutions. Retrieved September 16, 2015, from http://carnegieclassifications.iu.edu/

Jordan, T. C., Burnett, S. H., Carson, S., Caruso, S. M., Clase, K., DeJong, R. J., .. Hatfull, G. F. (2014). A broadly implementable research course in phage discovery and genomics for first-year undergraduate students. MBio, 5(1), e01051-13. https://doi.org/10.1128/mBio.01051-13

Kline, R. B. (2015). Principles and practice of structural equation modeling New York: Guilford.

Linn, M. C., Palmer, E., Baranger, A., Gerard, E., \& Stone, E. (2015). Undergraduate research experiences: Impacts and opportunities. Science, 347(6222), 1261757. https://doi.org/10.1126/science.1261757

Markus, H. R., \& Kitayama, S. (1991). Culture and the self: Implications for cognition, emotion, and motivation. Psychological Review, 98(2), 224-253. https://doi.org/10.1037/0033-295X.98.2.224

MassBioEd. (2016). The digest of biotech job trends in Massachusetts (3-month job trend report). Retrieved September 11, 2017, from www .massbioed.org/writable/files/massbioed_3-month_job_trend_report _q3_2016_copy1.pdf

Mullen, A. L., Goyette, K. A., \& Soares, J. A. (2003). Who goes to graduate school? Social and academic correlates of educational continuation after college. Sociology of Education, 76(2), 143-169.

National Research Council. (2011). Report of a workshop on science, technology, engineering, and mathematics (STEM) workforce needs for the U.S. Department of Defense and the U.S. defense industrial base. Washington, DC. https://doi.org/10.17226/13318

Nevill, S. C., \& Chen, X. (2007). The path through graduate school: A longitudinal examination 10 years after bachelor's degree. Postsecondary 
education descriptive analysis report (NCES 2007-162). Washington, DC: National Center for Education Statistics. Retrieved June 28, 2017, from https://eric.ed.gov/?id=ED495661

Olson, S., \& Riordan, D. G. (2012). Engage to excel: Producing one million additional college graduates with degrees in science, technology, engineering, and mathematics. Washington, DC: Retrieved November 6, 2014 from https://eric.ed.gov/?id=ED541511

Rodenbusch, S. E., Hernandez, P. R., Simmons, S. L., \& Dolan, E. L. (2016). Early engagement in course-based research increases graduation rates and completion of science, engineering, and mathematics degrees. CBE-Life Sciences Education, 15(2), ar20. https://doi.org/10.1187/cbe.16-03-0117

Rudy, D., Sheldon, K. M., Awong, T., \& Tan, H. H. (2007). Autonomy, culture, and well-being: The benefits of inclusive autonomy. Journal of Research in Personality, 41(5), 983-1007. https://doi.org/10.1016/j.jrp.2006.11.004

Ryan, R. M., \& Deci, E. L. (2000). Self-determination theory and the facilitation of intrinsic motivation, social development, and well-being. American Psychologist, 55(1), 68-78. https://doi.org/10.1037/0003-066X.55.1.68

Sadler, P. M., Sonnert, G., Hazari, Z., \& Tai, R. (2012). Stability and volatility of STEM career interest in high school: A gender study. Science Education, 96(3), 411-427. https://doi.org/10.1002/sce.21007

Satorra, A., \& Bentler, P. M. (2001). A scaled difference chi-square test statistic for moment structure analysis. Psychometrika, 66(4), 507-514. https:// doi.org/10.1007/BF02296192
Schultz, P. W., Hernandez, P. R., Woodcock, A., Estrada, M., Chance, R. C. Aguilar, M., \& Serpe, R. T. (2011). Patching the pipeline: Reducing educational disparities in the sciences through minority training programs. Educational Evaluation and Policy Analysis, 33(1), 95-114. https://doi.org/ 10.3102/0162373710392371

Tai, R. H., Qi Liu, C., Maltese, A. V., \& Fan, X. (2006). Career choice. Planning early for careers in science. Science, 312(5777), 1143-1144. https:// doi.org/10.1126/science.1128690

Walpole, M. (2003). Socioeconomic status and college: How SES affects college experiences and outcomes. Review of Higher Education, 27(1), 4573. https://doi.org/10.1353/rhe.2003.0044

Wei, C. A., \& Woodin, T. (2011). Undergraduate research experiences in biology: Alternatives to the apprenticeship model. CBE-Life Sciences Education, 10(2), 123-131. https://doi.org/10.1187/cbe.11-03-0028

Wentzel, K. R., \& Miele, D. B. (2016). Handbook of motivation at school (2nd ed.). New York: Routledge.

Wigfield, A., \& Eccles, J. S. (2000). Expectancy-value theory of achievement motivation. Contemporary Educational Psychology, 25(1), 68-81. https://doi.org/10.1006/ceps.1999.1015

Wiley, E. A., \& Stover, N. A. (2014). Immediate dissemination of student discoveries to a model organism database enhances classroom-based research experiences. CBE-Life Sciences Education, 13(1), 131-138. https://doi.org/10.1187/cbe.13-07-0140 